\title{
CHOOSING THE EXTENT OF PRIVATE PARTIPATION IN PUBLIC SERVICES: A COMPUTABLE GENERAL EQUILIBRIUM PERSPECTIVE
}

\author{
Omar Chisari* \\ Germán Lambardi* \\ Carlos A. Romero ${ }^{* * *}$
}

\begin{abstract}
Resumen
¿Qué determina la propensión a reducir o extender la propiedad pública? ¿Por qué esa propensión fue mayor en los años noventa? Las respuestas a estas preguntas dependen tanto de consideraciones macroeconómicas como microeconómicas. Respuestas correctas podrían ayudar también a evitar o prevenir reversiones ineficientes y frustraciones que pongan en peligro los procesos de reforma. Una perspectiva alternativa, que combina argumentos micro y macro, viene dada por los modelos de equilibrio general. El objetivo de este trabajo es explorar la racionalidad de la decisión de elegir de manera endógena entre las tecnologías de empresas de servicios públicos privadas y de propiedad estatal, en una economía en la que el presupuesto fiscal y el balance comercial deben estar en equilibrio. Las simulaciones confirman que la elección de la tecnología a ser usada en servicios de infraestructura depende de algunos parámetros profundos de eficiencia y costo. El modelo muestra que hay escenarios plausibles en los que la selección no es excluyente y que ambas tecnologías pueden coexistir.
\end{abstract}

Clasificación JEL: D58, H40

Palabras clave: servicios públicos - tecnología - equilibrio general computacional

\begin{abstract}
What determines the propensity to reduce or widen the extent of public ownership? Why has there been a propensity to privatize and concede public utilities in the nineties?

\footnotetext{
* Instituto de Economía, Universidad Argentina de la Empresa, Consejo Nacional de Investigaciones Científicas y Técnicas, CONICET, e.mail: ochisari@uade.edu.ar

** GREMAQ, Toulouse School of Economics, e.mail: glambardi@gmail.com

*** Instituto de Economía, Universidad Argentina de la Empresa, e.mail: cromero@uade.edu.ar
} 
The answers to these questions depend both on macroeconomic and microeconomic considerations. And correct answers could also help to avoid or prevent inefficient reversals and frustrations that jeopardize reform processes. An alternative perspective, that combines micro and macro arguments, is given by general equilibrium models. The objective of this paper is to explore the rationality of the decision of choosing in an endogenous way the implicit "technologies" of private and state owned operators of utilities in an economy that has fiscal budget and trade balance in equilibrium. The simulations confirm that the choice of the technology to be used for servicing infrastructure depends on deep parameters of efficiency and costs. The model shows that there are plausible scenarios where the selection is not all-or-nothing and that they can coexist.

Keywords: public services - technology - computable general equilibrium

\section{INTRODUCTION}

What determines the propensity to reduce or widen the extent of public ownership? Why has there been a tendency to privatise and concede public utilities during the nineties?

The answers to these questions depend both on macroeconomic and microeconomic considerations. Correct answers could also help to avoid or prevent inefficient reversals and frustrations that jeopardize reform processes.

On the microeconomic side, there are two prominent theories ${ }^{1}$. One, emphasizes the role of public ownership to resolve contractual problems and to influence the decisions of the firms in certain sensitive issues for the politicians; it is easier to control the decisions of the firm (on employment levels, for example) when the company is under state ownership. The other focuses on the self exclusion of private sector under government opportunism; if taxes and regulations are too unstable and endogenous, risk of arbitrariness discourages private investments, and public ownership is the only possibility.

On their side, macroeconomic considerations have focused in the need of controlling public deficits, obtaining revenues from privatisations and concessions,

\footnotetext{
${ }^{1}$ According to Esfahani and Ardakani (2004).
} 
fostering growth through efficiency enhancements, controlling the outflow of dividends that puts under stress the trade balance and obtaining price reductions via competitive environments.

One additional point to consider is whether it is an all-or-nothing choice. That is, could there be gains of having private operators coexisting and competing with a public enterprise? Two issues must be taken into account:

1) Efficiency gains given the reciprocal benchmarking. However, it is difficult to say why not benchmarking private operators and why a mix public/private is better.

2) Gains due to harder competition. But competition could prevail even between private operators. In fact, the presence of private operators could alleviate potential problems of moral hazard of public sector being involved simultaneously in operation and regulation.

In this paper, we focus in the case of sectors traditionally subject to regulation (like energy, water and sanitation, telecoms). We find it is not possible to dismiss an equilibrium for the economy such that both "technologies" could be operative simultaneously, helping to balance efficiency gains and trade balance result.

\section{THE GENERAL EQUILIBRIUM APPROACH}

An alternative perspective, that combines micro and macro arguments, is given by general equilibrium models. General equilibrium analysis gives a framework of consistency that impedes counting gains more than once, obliges to represent budget constraints of all agents -including transfers- and gives net welfare results after taking into account changes in relative prices and factor rewards. In fact, changes in factor rewards could change expected gains of privatisations and government activity...or not. And it is in the last case when arguments in favour of private operation are stronger. This perspective has not been fully explored for the study of regulatory regimes. And there are only a few examples -e.g. Chisari, Estache and Romero (1999). In this paper the objective is to explore the rationality of the decision of choosing the implicit "technologies" of private and public operators of utilities in an economy that has fiscal budget and trade balance in equilibrium.

In this paper we leave aside some interesting issues that should deserve more attention. Neither asymmetries of information nor political opportunism are included in the model. It is true that they are a cornerstone of regulatory 
economics, but at this stage the differences of dealing with them under public or private operation will only add confusion to the results. In fact, especially under high-powered regimes, the capacity and willingness to deal with asymmetries of information will be probably higher under private hands and that would be a reason for recommending private ownership operation. But, there has been less effort in appraising the trade-offs of reducing those costs.

We will focus on the core of the workings of the economy: what happens with relative prices and factor rewards after the privatisation or concession, what are the net welfares gains and their distribution and what is the sensitivity of the decision to changes in fundamental parameters, like the cost of capital. In broad terms, we will assume that the extreme cases of public and private operation have the following differences:

- Public enterprises show lower efficiency levels in the use of intermediate inputs and employment.

- This inefficiency implies that public enterprises must be subsidised, and therefore, that taxes or prices of utilities services must be higher.

- This inefficiency is also present in the investment process: one unit of investment produces more units of capital installed under private operation (or fewer units of investments are needed to compose one unit of capital).

- However the share of imported intermediate inputs is higher in the case of private operators, since new investments and methods are complementary of inputs and services provided by the rest of the world.

- Capital reward of private operators in determined basically by its cost of opportunity in the rest of the world.

Beyond short term increases in revenue for the governments, efficiency gains for the economy could justify higher presence of private sector. Given these elements, the typical choice will involve:

- To take into account that evidence tends to confirm that under public hands inefficiencies are higher, that more resources will be necessary to operate utilities diverting them from other (valuable) activities, and that subsidies will have to be covered with taxes or higher prices. This creates additional costs due to distortions and inefficiencies in the allocation of resources.

- Though private operators are more efficient, productivity of capital in the rest of the world becomes a relevant benchmark as the minimum required reward for private capital. The potential transfer of dividends abroad requires a positive trade balance. The economy will enjoy higher efficiency and performance standards, 
but at the cost of having to devote more resources to export markets (depending also on the use made of resources obtained from privatisation or concession, not considered here).

So, the basic comparison can be reduced to the minimum cost choice between 1) increasing exports (with local effort and consumption sacrifice) or 2) paying for inefficiencies and costs of misallocation of resources due to subsidisation. Our aim is to give a general equilibrium perspective to the questions posed at the beginning of this paper and to estimate thresholds for the cost of capital and public funds full costs that explain rational choices.

There are some provisos to take into consideration. The results must be examined both under full employment and with unemployment; in the last case, the results will depend on the rule of indexation of wages. Under unemployment, efficiency gains will be more important for obtaining increases in scales of operation that will influence positively welfare.

\section{BASIC ANALYTICAL STRUCTURE}

The analysis is based on a standard CGE model with regulation and service obligations (see Box 1). So the economy must choose between: 1) a local technology provided by the public enterprises, or 2) an updated -probably capital intensive- technology that uses mobile capital.

A fundamental difference of these technologies is that while capital is considered a sunk cost for public enterprises, that is not so for private operators. However, in our more general model though these conditions can be relaxed. The idea is to compare the on going model -the public enterprises technology- with a new one, more demanding in terms of capital investments.

\section{Regulatory Regimes and Service Obligations in a CGE}

Service obligation is interpreted as the passive adjustment of services supply to demand in the regulated sector. This assumption prevents need to rely on rationing which is quite realistic in the context of modern infrastructure reforms. If this assumption were not included, we would need to accept some form of rationing of customers (households or firms), and this will make any model much more complicated and ad-hoc. 
Most regulatory regimes establish explicitly this obligation in the contract, and its violation has not only direct economic costs but also hinders on the reputation of the firm. Service obligation increases costs to the firm (real and expected) and is compensated with the tariff and, very often, with the commitment by the regulator of protecting incumbents by legally blocking the entry of new competitors. A temporary "no entry" condition is, in fact, a second important characteristic of modern infrastructure reforms, which guarantees a return on assets, when perceived commercial risk levels could be aggravated by the concern for entry and become a participation constraint for the private sector.

With the Service Obligation hypothesis, there are two possible cases. In the first case, there is enough installed capacity to cover the necessities of clients and the main issue is for the firm to get a subsidy to cover the difference between marginal cost and regulated price. In the second case, the capacity is insufficient and additional investment is needed. This second option (with constant marginal costs) is used exceptionally when demand becomes too high. For the first option, we assume that the subsidy is paid by the shareholders of the firm in the case of the price-cap regime. With this strategy, existence of equilibrium can be shown using the proofs already available for the standard general equilibrium models with taxes. The price-cap or the rate-of-return regulation can be interpreted as special mark-up rules that are in fact taxes for which the revenue accrues to (or is extracted from) the owners of the firms.

To simplify, it may be useful to complement the discussion with a graphic beginning with the model of alternative technology. In fact, Graph 1 shows the case of an alternative technology when demand $\left(D_{a}\right)$ is low enough as to have excess of installed capacity. $P_{R}$ and $q_{R}$ denote the tariff in terms of the numeraire and the production level in the regulated sector, respectively. MC represents the marginal cost of the existing technology (the increasing segment) and an alternative technology (the constant marginal cost section of the curve), and $1 / \mu$ stands for the benchmark regulated price.

Given $\mathrm{D}_{\mathrm{a}}, p_{R}$ should fall to $p_{R^{*}}^{0}$. However, a tax $t$ is imposed (mark-up) to compensate owners of capital so that $p^{1}{ }_{R}(1+t)=p^{*}{ }_{R}=1 / \mu$

"Tax" revenue is transferred from customers to shareholders of the regulated firm. This $t$ could be negative as it is shown in Graph 2, that it is a subsidy $s$. If an alternative technology does not exist, the firm will continue operating if the additional units (A) marginal costs are covered (triangle S). Since the obligation of service was established in the original contract between the regulators and 
shareholders, we assume that the shareholders cover the excess of costs -implicitly in the form of a subsidy to the operative management of the firm. This internal subsidy $s$ is depicted in the figure below; in this case $s$ is computed so that net price to customers equals the price-cap settled at level $p_{R}$.

In summary, Graph 2 shows the case of an internal subsidy, funded with a tax on the shareholders of the regulated firm. When shareholders are foreign, this subsidy will be accompanied by an inflow of capital that reduces the need of trade surplus. Graph 2 also illustrates the case when the firm has the alternative of importing international capital. The incremental cost of the new technology is given by $w^{*} A / \mu$, where $w^{*}$ is the foreign factor reward and $\mu$ its average productivity. The firm will compare this cost with $\mathrm{S}$, to choose the method for servicing the market. However, this will have consequences on the current account; if the firm covers the deficit with the existing technology there will be an inflow of capital (though temporary); instead if the alternative technology is employed, the additional reward of foreign factors will impose a burden.

The literature on existence of equilibrium with taxes - see Shoven and Whalley (1973) and Ginsburgh and Keyzer (1997) - can be used in this case with minor adaptations.

Graph 1- Non-operative price-cap

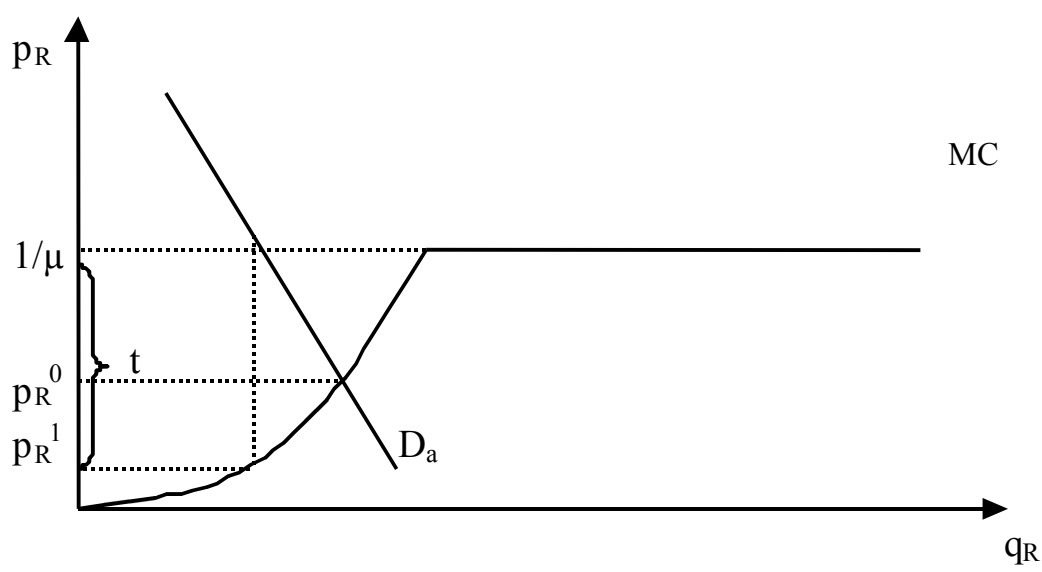




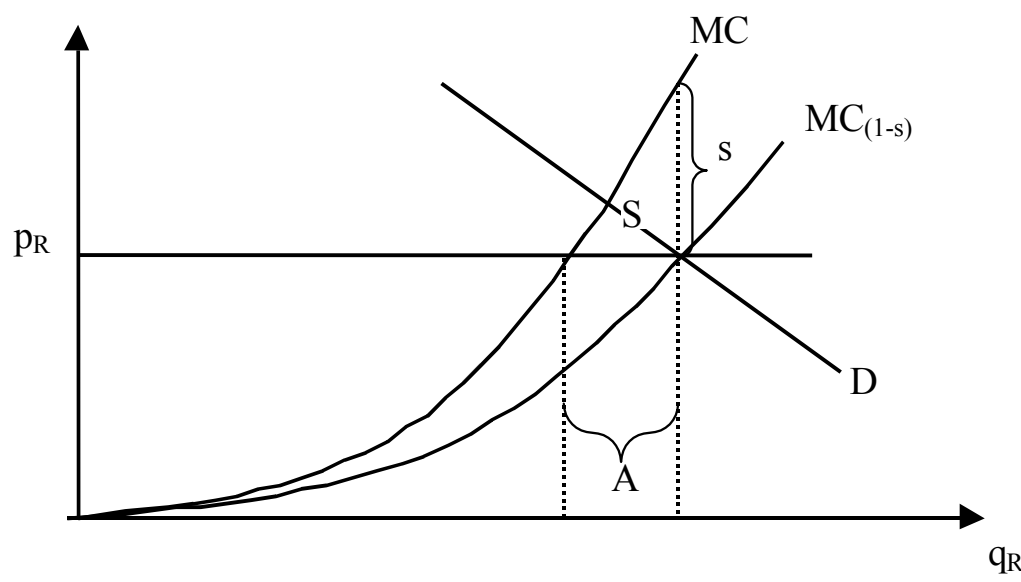

Source: Chisari, Estache, Lambardi y Romero (2003)

To simulate the model we will use a Social Accounting Matrix of reduced dimensions that captures the main characteristics of a developing economy, in terms of share of public services in GDP. There is a basic structure that will be specialized to consider the public and private technologies. For the sake of presentation, the public technology is discussed first.

Each sector uses two different factors: one mobile, labor, and one non mobile, specific capital. There are four domestic sectors of production (activities): $\mathrm{I}=\{1,2, \mathrm{~N}, \mathrm{R}\}$, two of them are tradable sectors, $\mathrm{T}=\{1,2\}$, and the rest are producers of goods and services that are not tradable; sector $\mathrm{N}$ produces services and sector $\mathrm{R}$ represents sectors under regulation.

Each activity produces only one commodity represented by $\mathrm{J}=\{1,2$, $\mathrm{N}, \mathrm{R}\}$. We assume that the utility and production functions correspond to the traditional neoclassical version. However, production sectors are related through input-output transactions, which play an important role in understanding the net impact of regulation on the economy. Prices of tradable goods are determined by the rest of the world, and domestic agents also import consumption goods that are imperfect substitutes of local production. In this version, it is assumed that imported goods are not used for production. 
The analytical representation of the aggregated regulated sector in this section deserves more attention. Though it is natural to think that the production function of that sector should exhibit some economies of scale or sub-additivity, we will assume that there are not non-convexities once specific capital is installed. This is a simplification with obvious theoretical costs, but it also contributes to concentrate our effort in determining the impact of regulatory mechanisms and not on the properties of the production set ${ }^{2}$. The public technology works with installed capital. The alternative technology gives some hints on the long run effects; in that case, we assume constant returns to scale.

The domestic household

We assume that there is an only domestic agent that makes the decision on the consumption plan and receives all factor rewards (except for the regulated firm) and profits. So, we will not be paying attention to personal income distribution, though we will pay more attention to factor distribution. This agent collects also all taxes and grants subsidies. Net welfare of this household will therefore represent social welfare.

The domestic agent maximizes the utility function $u\left(c_{1}, c_{2}, c_{N}, c_{R}, m\right)$ subject to:

$$
\sum p_{T} c_{T}+p_{R} c_{R}+p_{N} c_{N}+p_{m} m=w \bar{L}+\sum r_{I} \bar{K}_{I}+\theta \pi_{R}^{*}+\theta t p_{R} G\left(L_{R}, K_{R}\right)
$$

where $\theta$ is the share of domestic agents in profits of the regulated sector $\pi_{R}^{*}$ and the last term corresponds to the compensatory transfer from domestic customers $(\mathrm{t}>0)$ or to the firm from its shareholders $(\mathrm{t}<0)$. Under public ownership, $\theta=1$. In both cases, under price cap, $t$ is computed so that $p_{R}=1 / \mu(1+t)$. From utility maximization, we obtain the familiar first order conditions:

$$
\begin{aligned}
& u_{c_{T}}^{\prime} / u_{m}^{\prime}=p_{T} / p_{m} \\
& u_{R}^{\prime} / u_{m}^{\prime}=p_{R} / p_{m} \\
& u_{N}^{\prime} / u_{m}^{\prime}=p_{N} / p_{m}
\end{aligned}
$$

\footnotetext{
${ }^{2}$ Dierker et al (1985) present an analysis of the existence of equilibrium when there are special pricing rules.
} 
$c_{T}$ is consumption of domestic tradable goods, $c_{R}$ is the consumption of goods and services under regulation and $m$ are imports (a good produced abroad but not domestically) and $p_{p}, p_{R}$ and $p_{m}$ are their respective prices. $w$ is the wage rate and $r_{I}$ is the rate of return on capital in each sector. $\bar{L}$ stands for labor supply (determined endogenously in the computed version of model, so there is a demand for leisure) and $\bar{K}$ represents the domestic agent endowments of capital.

The domestic production sectors

$F, H$ and $G$ are the production function of the tradable, non-tradable and regulated sectors, respectively. We assume constant returns to scales in all cases. As we mentioned, this is a simplification that helps to avoid problems of existence of equilibrium. However, in this version, once capital is allocated to a sector it becomes specific and non mobile.

\section{a. Tradable Sectors}

There is one firm that maximizes profits in each tradable sector. The net price for the firm is the price to consumers less the cost of intermediate inputs.

$$
\pi_{T}=\left[p_{T}-\sum_{J \neq T} a_{J, T} p_{J}-a_{R, T} p_{R}-a_{N, T} p_{N}\right] F_{T}\left(L_{T}, K_{T}\right)-w L_{T}-\sum_{T} r_{T} K_{T}
$$

for every $T=1,2$. Notice that the incentive to produce is given by the price net of intermediate inputs costs. The maximum profit conditions are:

$$
\begin{aligned}
& {\left[p_{T}-\sum_{J \neq T} a_{J, T} p_{J}-a_{R, T} p_{R}-a_{N, T} p_{N}\right] F_{L}=w} \\
& {\left[p_{T}-\sum_{J \neq T} a_{J, T} p_{J}-a_{R, T} p_{R}-a_{N, T} p_{N}\right] F_{K}=r_{T}}
\end{aligned}
$$

In both cases, the value of marginal product (corrected for inputs expenses) is equalized to the reward of the factor. Notice that we are not assuming export or import taxes but they can be introduced easily as ad valorem taxes. 
b. Non-tradable Sector

Services and other non tradable goods are produced using labor and capital. Capital is specialized and non mobile. Equation (8) corresponds to the definition of profits, and equations (9) and (10) to optimization conditions:

$$
\begin{aligned}
& \pi_{N}=\left[p_{N}-\sum_{T} a_{T, N} p_{T}-a_{R, N} p_{R}\right] H\left(L_{N}, K_{N}\right)-w L_{N}-r_{N} K_{N} \\
& {\left[p_{N}-\sum_{T} a_{T, N} p_{T}-a_{R, N} p_{R}\right] H_{L}=w} \\
& {\left[p_{N}-\sum_{T} a_{T, N} p_{T}-a_{R, N} p_{R}\right] H_{N}=r_{N}}
\end{aligned}
$$

c. Public utilities or regulated sector

As we mentioned above, the regulated firm is treated as a neoclassical firm. There is no entry and service obligations are established. Net price is obtained as the difference between the regulated price and intermediate cost.

$$
\pi_{R}=\left\lceil p_{R}-\sum_{T} a_{T, R} p_{T}-a_{N, R} p_{N}\right\rceil G\left(L_{R}, K_{R}\right)-w L_{R}
$$

Notice that in this expression $K_{R}$ is given. The total rate of return of this sector is $r_{R}=\pi_{R} / K_{R}$. The optimality condition for profits is:

$$
\left[p_{R}-\sum_{T} a_{T, R} p_{T}-b_{N, R} p_{N}\right] G_{L}=w
$$

$a_{R, T}$ and $a_{T, R}$ are input-output coefficients. They are used to represent also technical gains due to privatization. A reduction in $a_{T, R}$ is an improvement of efficiency internal to the public service firms, which reduces the requirement of intermediate inputs per unit of product. $a_{R, T}$ is a reduction of the requirement of regulated input per unit of tradable output (due to a better performance of private operators). 
Rest of the world

a. Production sectors

The rest of the world produces substitutes for our exports and import goods, using a factor of production $\mathrm{F}$.

$$
\begin{aligned}
& \pi_{m}^{*}=p_{m} \alpha\left(F_{m}\right)-w^{*} F_{m} \\
& \pi_{T}^{*}=p_{T} \beta_{T}\left(F_{T}\right)-w^{*} F_{T} \\
& p_{m} \alpha^{\prime}=w^{*} \\
& p_{T} \beta_{T}^{\prime}=w^{*} \\
& m^{s}=\alpha\left(F_{m}\right) \\
& x^{s}=\beta_{T}\left(F_{T}\right)
\end{aligned}
$$

In the case of $\alpha^{\prime}$ and $\beta_{T}^{\prime}$ constants, international terms of trade will be given by $p_{T} / p_{m}=\alpha / \beta_{T}$ (small economy assumption).

$\pi^{*}{ }_{m}$ and $\pi_{T}^{*}$ represent profits in the rest of the world industries that produce import goods and perfect substitutes of tradable goods. $w^{*}$ is the price of one unit of value added in the rest of the world.

$F_{m}$ and $F_{T}$ are factor quantities employed in the corresponding industries. The production functions: $\alpha\left(F_{m}\right)$ and $\beta_{T}\left(F_{T}\right)$ give the total supply in equations (16), (17) and (18).

b. Households

Consumers in the rest of the world receive the rewards of foreign factors, including capital installed in the regulated sector as well as profits in that sector. It maximizes a utility function $v\left(x_{T}, m^{*}\right)$ that depends on the consumption of our tradable goods and of import goods. Their budget condition is:

$$
p_{m} m^{*}+p_{T} x_{T}=w^{*} \bar{F}+(1-\theta) \pi_{R}+\pi_{m}^{*}+\sum_{T} \pi_{T}^{*}+t p_{R} G\left(L_{R}, K_{R}\right)
$$

Foreign agents receive also profits and capital return of the regulated sector, as well as the wage rate (cost of capital) $F$ and the proceedings of the mark-up factor. $X_{T}$ are exports that are domestic tradable goods bought by the foreign agent. The 
last term in equation (19) stands for the endogenous mark-up (positive) or internal subsidy (negative) computed as the difference between the benchmark tariff $1 / \mu$ (as seen by customers) and $p_{R}$.

Market equilibrium conditions

Equations (20) to (27) represent the equilibrium conditions for factors used domestically. Equation (23) is the equilibrium condition for the foreign factor. Equations (25) to (27) correspond to equilibrium in markets for goods: regulated, non regulated and imports.

$$
\begin{aligned}
& \bar{L}=L_{1}+L_{2}+L_{R}+L_{N} \\
& \bar{K}_{T}=K_{T} \quad(T=1,2) \\
& \bar{K}_{N}=K_{N} \\
& \bar{F}=F_{m}+\sum_{T} F_{T} \\
& G\left(L_{R}, K_{R}\right)+q_{R}=\sum_{T} a_{R, T} F_{T}\left(L_{T}, K_{T}\right)+a_{R, N} H\left(L_{N}, K_{N}\right)+c_{R} \\
& F_{T}\left(L_{T}, K_{T}\right)+x_{T}^{s}=a_{T, R} G\left(L_{R}, K_{R}\right)+a_{T, N} H\left(L_{N}, K_{N}\right)+c_{T}+x_{T} \\
& H\left(L_{N}, K_{N}\right)=\sum_{T} a_{N, T} F_{T}\left(L_{T}, K_{T}\right)+a_{N, R} G\left(L_{R}, K_{R}\right)+c_{N} \\
& m^{s}=m+m^{*}
\end{aligned}
$$

Trade balance

We can now see how the relation between the mark-up factor (and its mechanism of adjustment) and the trade balance arises in the model. From (1):

$$
p_{R} c_{R}+\sum_{I /\{R\}} p_{I} c_{I}+p^{*} m=w \bar{L}+\sum_{I /\{R\}} r_{I} \bar{K}_{I}+\theta \pi_{R}+\theta t P_{R} G\left(L_{R}, K_{R}\right)
$$

Since:

$$
p_{R} c_{R}+\sum_{I /\{R\}} p_{I} c_{I}+p x=w \bar{L}+\sum_{I /\{R\}} r_{I} \bar{K}_{I}+\pi_{R}+t P_{R} G\left(L_{R}, K_{R}\right)
$$


Then the trade balance is:

$$
p x-p^{*} m=(1-\theta)\left[\pi_{R}+t p_{R} G\left(L_{R}, K_{R}\right)\right]
$$

The left hand side is the trade balance and the right hand is the foreign share in regulated sector profits. ${ }^{3}$

This equation shows the link between the regulatory regime and the trade account. However this expression is only an example, for national ownership is not a sufficient condition to reduce the stress on the trade balance; even domestic agents could reveal preference for foreign assets or goods, and put pressure on the trade balance. On the other hand, foreign ownership is not necessarily a source of stress on trade surplus; that would be the case if profits were reinvested in the country. Therefore, our case only intends to give an illustration of potential results. A more general model should include more elaboration on the domestic and foreign agents' portfolio and investment decisions.

\section{THE SOCIAL ACCOUNTING MATRIX}

To keep the model within conceptual explorations, we constructed a small SAM that reflects acceptable proportions for a developing economy with relevant state owned enterprises participation.

The SAM represents an initial condition with prevalence of the state companies' technology. More than ever, this is a theoretical exploration using numbers, in the sense of Piggott and the model is a special case of the general system presented above.

Table 1 presents the SAM. The rows show markets and the columns budgetary constraints. Notice that the subsidy granted to the public utilities in government hands is represented as a positive entry of $\$ 12973$ in the corresponding column. H, PU, RW and G stand for Household, Public Utility and Rest of the World and Government, and L, K and FF for labor, specific capital and mobile capital respectively. M1 and M2 represent imports; in this version we do not have imports of intermediate goods to be used by industries.

\footnotetext{
${ }^{3}$ The trade balance must compensate the current account result. Notice that it is not influenced by inflows or outflows of capital "of the same period": the net impact is: $-r_{R} K_{R}$.
} 
TABLE 1- A SAM for modeling alternative technologies

\begin{tabular}{|l|c|c|c|c|c|c|c|c|c|}
\hline & Agriculture & Industry & Services & $\begin{array}{c}\text { P.U. } \\
\text { (old) }\end{array}$ & $\begin{array}{c}\text { P.U. } \\
\text { (new) }\end{array}$ & H & G & RW & Total \\
\hline Agriculture & 26,931 & $-18,422$ & -377 & -163 & -2 & $-2,058$ & & $-5,909$ & 0 \\
Industry & $-4,479$ & 100,285 & $-16,549$ & $-4,533$ & -48 & $-55,760$ & & $-18,916$ & 0 \\
Services & $-2,407$ & $-18,658$ & 168,206 & $-6,381$ & -67 & $-140,693$ & & & 0 \\
P.U. (old) & -605 & $-5,955$ & $-5,424$ & 23,778 & & $-11,794$ & & & 0 \\
P.U. (new) & -7 & -72 & -66 & & 285 & -140 & & & 0 \\
L & $-4,832$ & $-22,636$ & $-64,477$ & $-25,675$ & -68 & 117,688 & & & 0 \\
K & $-14,600$ & $-34,542$ & $-81,313$ & 0 & 0 & 130,455 & & & 0 \\
FF & & & & & -100 & & & 100 & 0 \\
Subsidy & & & & 12,973 & & & $-12,973$ & & 0 \\
Tax & & & & & & $-12,973$ & 12,973 & & 0 \\
M1 & & & & & & -732 & & 732 & 0 \\
M2 & & & & & & $-23,993$ & & 23,993 & 0 \\
\hline Total & 0 & 0 & 0 & 0 & 0 & 0 & 0 & 0 & 0 \\
\hline
\end{tabular}

Source: Own elaboration

The state owned companies' technology produces slightly more than $1 \%$ of total sales of infrastructure services ( $\$ 285$ of $\$ 24063$ ), and receives a subsidy from the government of about $35 \%$ of total costs. This subsidy is financed with a tax on the household's income.

The model is computed using MPSGE developed by Tom Rutherford.

\section{ALTERNATIVE TECHNOLOGIES AND MODEL SOLUTIONS}

The first solution involves computing an initial subsidy that maintains the state owned company working at its observed levels however its inefficiency. Service obligations are met with the installed technology, less efficient in use of intermediate inputs and labor than the imported one. 
For the initial benchmark calibration we assume that $L_{R}$ is used in fixed coefficients by the domestic state owned company, so that instead of (12) we have the non negativity condition:

$$
\sum a_{T, R} p_{T}+b_{N, R} p_{N}+a_{L, R} w-s \geq 0
$$

The subsidy $s$ is computed initially under the condition that excessive costs of the state owned enterprise are compensated by the government, given a certain level of production. That is, $s$ is determined to replicate given productions of the state owned enterprise and of the private owned company; for example, if $70 \%$ of total production is obtained from the state owned company, and the rest from the alternative technology, $s$ is computed to match those observed levels of production. The subsidy is financed with taxes on households' total income to minimize distortions in this static model; this first simulation assumes therefore that taxes do not create costs of distortion.

The assumption on the alternative technology for the simulations is that it exhibits constant returns to scale, uses domestic intermediate inputs and mobile capital to produce the regulated good or service. For this technology we also assume fixed coefficients in this presentation, and the price is fixed at its cost of production:

$$
\sum a_{T, R}^{*} p_{T}+b_{N, R}^{*} p_{N}+a_{L, R}^{*} w^{*}=p_{R^{\prime}}^{*}
$$

Here the symbol $(*)$ stands for the input coefficients of the mobile capital technology, and $p_{R}^{*}$ is the price of the infrastructure service when produced with the imported standards.

It is assumed that the rate of profit is given at the level of the cost (of opportunity) of value added of the rest of the world, and that capital in the regulated sector is not sunk. It is an implicit cost-plus mechanism with a minimum rate of return given by the international productivity of capital. Therefore $K_{R}$ becomes one of the variables to be determined in the solution; it is included in equation (11) in the definition of profits, with a cost given by $w^{*}$. The value added used in production domestically will also enter in equation (23), since it is an additional demand for value added of the rest of the world. The trade balance equilibrium condition becomes simply: 


$$
p_{T} x-p_{m} m=\pi_{R}+w^{*} K_{R}
$$

Given the initial subsidy $s$, the simulations explore the effects of reductions in $w^{*}$ that leave relative prices of exports and imports unchanged. Then, the computable model chooses the less costly alternative between the internal cost of the subsidy and the "imported" technology, so to maximize welfare of the domestic household.

Table 2 shows the results of three simulations. The first two search for a threshold for the cost of mobile capital: which is the level of $w^{*}$ such that the local public technology is substituted by the new imported technology? The first scenario contemplates full substitution and the second one, partial substitution. That is, we calibrate the model so that $99 \%$ of the total production of utilities is produced using the old technology and only one percent corresponds to the mobile capital case; full substitution occurs when these percentages are reverted. It can be seen that a reduction of approximately $12 \%$ in the rate of return requested by the rest of the world leads to a full replacement. About $6 \%$ is needed to replace half of the share of domestic technology. Both simulations take as given the initial subsidy for the state owned enterprise. In our third simulation, instead of reducing $w^{*}$ we evaluate the effects of reducing the subsidy $s$ for a given level of the cost of mobile capital. Notice that in this case, the old and public technology is fully substituted when the subsidy is reduced $15 \%$.

The effect of reductions in the cost of mobile capital and in subsidies to state owned companies are shown as changes in terms GDP and households' welfare. The latter is computed as the Equivalent Variation. When the new technology is fully adopted, households enjoy welfare levels that are equivalent to $5.6 \%$ and $5 \%$ of their benchmark income. It is confirmed that the new technology is more demanding for the trade balance and requires an additional export effort by the economy; this effort is equivalent to $w^{*} K_{R}$ since we assume that we are in a stationary state, so that initial entry of capital $+K_{R}$ is compensated in the same period with an outflow $-K_{R}$. When the reimbursement of the principal encompasses several periods, the stress on the forthcoming trade balances will be higher and the net effect will depend also on the gains obtained with the initial inflows and the uses given to those funds.

Table 2 also alerts on potential conflicts. Both nominal and real wages fell in all scenarios since labour is not mobile, and its price is being reduced until the new technology is adopted. 
It is important to remember that these simulations have been performed using non-distortionary taxation and so we should expect faster substitution when taxes on subsets of goods are not charged, or when the tax structure is not even.

TABLE 2 - Results of simulations

\begin{tabular}{|l|c|c|c|}
\hline & $\begin{array}{c}\text { Simulation } \\
\text { 1: Foreign } \\
\text { Capital Price } \\
\text { Reduction } \\
\text { until domestic } \\
\text { production is } \\
\text { replaced }\end{array}$ & $\begin{array}{c}\text { Simulation } \\
\text { 2: Foreign } \\
\text { Reduction } \\
\text { until half } \\
\text { domestic } \\
\text { production is } \\
\text { replaced }\end{array}$ & $\begin{array}{c}\text { Simulation } \\
\text { 3: Domestic } \\
\text { subsidy } \\
\text { reduction } \\
\text { until domestic } \\
\text { production is } \\
\text { replaced }\end{array}$ \\
\hline GDP (\% variation) & 7.2 & 3.8 & 7.1 \\
\hline Agriculture activity level & 4.5 & 2.3 & 4.8 \\
\hline & & & \\
\hline Manufactures activity level & 11.3 & 5.8 & 11.6 \\
\hline Services activity level & 6.6 & 3.4 & 6.5 \\
\hline Utilities activity level & 3.5 & 2.4 & 2.5 \\
\hline $\begin{array}{l}\text { Old Tech. Participation in Public } \\
\text { utilities production (benchmark 99\%) }\end{array}$ & $1 \%$ & $50 \%$ & $1 \%$ \\
\hline $\begin{array}{l}\text { New Tech. Participation in Public } \\
\text { utilities production (benchmark 1\%) }\end{array}$ & $99 \%$ & $50 \%$ & $99 \%$ \\
\hline Consumers'Prices (\% variation) & -3.0 & -1.6 & -3.2 \\
\hline Agriculture prices & 0.4 & 0.2 & 0.4 \\
\hline Manufactures prices & 1.1 & 0.6 & 0.9 \\
\hline Services prices & -4.0 & -2.2 & -4.8 \\
\hline Utilities prices & -8.8 & -4.7 & -4.4 \\
\hline Exports (\% variation) & 44.3 & 23.1 & 48.5 \\
\hline Imports (\% variation) & 5.6 & 2.8 & 5.0 \\
\hline Household Welfare (\% variation) & 5.6 & 2.8 & 5.0 \\
\hline Foreign Capital Price (\% variation) & -11.6 & -6.2 & 0.0 \\
\hline Domestic Subsidy (\% variation) & - & - & -15.4 \\
\hline Rates of Return (\% variation) & 6.1 & 3.1 & 5.2 \\
\hline Agriculture & 5.4 & 2.8 & 5.6 \\
\hline Industry & 15.7 & 8.0 & 15.2 \\
\hline Services & 2.2 & 1.0 & 0.8 \\
\hline Wages (\% variation) & -11.7 & -6.3 & -12.6 \\
\hline Source Own & & & \\
\hline & & & \\
\hline
\end{tabular}

Source: Own elaboration 


\section{LESSONS FROM THE EXERCISES}

Our simulations confirm that the choice of the technology to be used for servicing infrastructure depends on deep parameters of efficiency and costs.

It does not say whether or why state owned companies could be more inefficient than private ones, but given those inefficiencies that create costs in terms of resources and distortions, it says that the operative technology is not necessarily unique; the share of total production that is served using each technology depends on the magnitude of waste and on the costs in the allocation of resources relative to the price of mobile capital (and implicitly on the export effort of the country).

We have not looked at additional characteristics of the technologies that could favour one over the other. For example, corruption and passive deficit could lead to hyperinflation in a context of state owned enterprises, and chronic misallocation of resources could reduce investments and destroy the base of capital of government companies. Also, we have not considered potential constraints on less developing countries' exports for they could also increase significantly the cost of raising foreign currency to honour the payment of dividends to mobile capital. Also, we have not considered the optimal regime of competition between both kinds of firms, and the potential problems of moral hazard created by determining regulations that could favour state owned companies. We have not evaluated the effects of the initial inflow of capital due to privatization or concession; well managed, those funds could overcome the stress on the trade balance. Nor we considered the possibility of using domestic capital to produce the service of infrastructure.

We did not do many things. Then, what did we do? Our intention was to consider only some cases that could give a confirmation of the basic intuition, and we confirmed that general equilibrium effects are relevant, that both technologies can coexist to maximize social welfare, and finally that CGE can be an useful instrument for ex ante evaluation on the optimal choice of industrial organization of big sectors of the economy.

\section{REFERENCES}

Chisari O., A. Estache and Romero, C. (1999), "Winners and Losers of Privatizations and Regulation of Utilities: Lesson from a General Equilibrium Model of 
Argentina," The World Bank Economic Review, Vol.13, (2), pp.357-378.

Chisari, O., A., Estache, Lambardi, G. and Romero, C., (2003), "Trade performance and regulatory regimes", Anales de la Asociación Argentina de Economía Política,

Dierker E., Guesnerie, R. and Neuefeind, W., (1985), "General Equilibrium When Some Firms Follow Special Rules," Econometrica, Vol.53, (6), pp.13691393.

Esfahani, H. and Ardakani, A., (2004), "What Determines the Extent of Public Ownership?" University of Illinois and University of Manchester conference on "Regulation of Development and the Development of Regulation", printed in Quarterly Review of Economics and Finance.

Ginsburgh V. and Keyzer, M., (1997), The Structure of Applied General Equilibrium Models, (Cambridge MA: The MIT Press).

Shoven, J. and Whalley, J. (1973), "General Equilibrium with Taxes: A Computational Procedure and an Existence Proof', The Review of Economic Studies, Vol.40, (4), pp. 475-489. 